\title{
Physical Activity Component Should be Included when Designing National Child-Obesity Program: The Rapid Review of Multi-Component Child Obesity Intervention Programs
}

\author{
Don Hyung Lee ${ }^{1^{*}}$
}

${ }^{1}$ Korea Health Promotion Institute, Korea

\author{
Received: May 29, 2020 \\ Accepted: July 23, 2020 \\ Published online: July 31, 2020 \\ Keywords: \\ Child Obesity \\ Diet \\ Multi-component \\ Physical Activity \\ Rapid Review
}
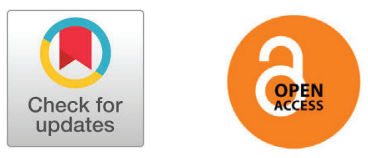

\section{ABSTRACT}

OBJECTIVES The prevalence of child obesity is steadily increasing in Korea, thus government needs to seek for effective intervention programs to counteract current epidemics. This study sought to find proven effective child obesity programs implemented in other countries in order to provide policy recommendation. We report the results of rapid review of child obesity programs which were implemented outside of Korea.

METHODS A search of multiple databases (NICE Evidence Search, Open Grey, Grey Literature Report, National Cancer institute: research-tested intervention programs) was conducted to identify relevant research articles published after January 2010.

RESULTS 11 studies met the inclusion criteria after systematic screening. Most of the included studies used physical activity \& diet/nutrition at the same time, while school was the most common location for the intervention. 5 studies showed improvement in obesity related outcomes. Interventions contained physical activity \& diet/nutrition or physical activity \& psychological coaching, and intervention implemented in school, healthcare facility, summer camp, and after-school class were shown effective.

CONCLUSIONS Considering the results of current review, multi-component intervention which includes physical activity is recommended when designing child obesity program. The location of the intervention should be school to maximize its effectiveness.

๑) The Asian Society of Kinesiology and the Korean Academy of Kinesiology
서론

1980년대부터 과체중을 포함한 전 세계 아동의 비 만율은 꾸준히 증가하여 2013의 비만율은 1980대비 $47 \%$ 가 증가하였다[1]. 현재 우리나라의 아동·청소년 비만율 역시 꾸준히 증가하고 있다. 아동·청소년 비만 율은 2007년 $11.6 \%$ 에서 2017년에는 $17.3 \%$ 로 증가하 였고 연령대가 높아질수록 더 늘어나는 양상을 보이고

*Correspondence: Don Hyung Lee, Department of Health Policy and Research, Korea Health Promotion Institute, 24th Fl., Namsan Square, 173 Toegye-ro, Jung-gu, Seoul, Korea; Tel: +82-3781-3500; Fax: +82-3781-3579; E-mail: donlee@khealth.or.kr
있다. $\mathrm{OECD}$ (경제협력개발기구)에 따르면 우리나라 남 자 아동·청소년의 비만율(과체중 포함)은 $26 \%$ 로써 이 미 $\mathrm{OECD}$ 의 평균 비만율(과체중 포함)인 $25.6 \%$ 를 넘어 섰다. 따라서 아동비만에 대한 정부의 대응은 선택이 아 닌 필수사항이 되었다고 할 수 있다.

아동시기의 비만은 인체 대부분의 장기에 영향을 끼 치며 천식[2], 폐쇄성 수면 무호흡, 제2종 당뇨[3]와 같 은 질환의 발병 가능성을 현저히 높인다. 아동비만은 심 혈관질환의 위험요인인 고혈압, 고콜레스테롤혈증, 고 중성지방혈증 등과도 관계가 있다[4]. 이 밖에도 아동 비만은 정신건강에도 안 좋은 영향을 끼친다. 선행연구 
에 따르면 비만아동은 자신감 부족을 경험하거나 왕따의 대상이 될 수도 있다고 한다[5]. WHO(세계보건기구)는 이미 비만을 질병으로 분류 하였고 대장암, 신장암, 간암 등 여러 암을 유발하는 주요 요인으로 제시하였다[6].

아동·청소년의 비만이 심각한 문제인 이유는 아동시 기의 비만은 건강에 악영향을 끼치는 한편 성인 비만으 로 이행할 가능성이 높고[7-9], 성인기로 이행된 비만 은 심각한 질병과 조기 사망의 위험을 증가시키 때문이 다[10]. Whitaker 등[8]의 비만아동의 후향적 코호트 연구에 따르면 6세 이상 비만 아동의 $55 \%$ 가 성인비만 으로 이행 하였고 10 14세 비만 청소년의 $75 \%$ 가 성인 비만으로 이행 하였다. 그리고 시뮬레이션 모델을 사용 하여 아동이 35세 성인이 되었을 때의 비만율을 예측한 Ward 등 [9]은 2세 비만 아동의 $74.9 \%$ 가 성인비만으 로, 19 세 비만 청소년의 $88.2 \%$ 가 성인비만으로 이행할 것이라고 예측하였다.

비만은 건강뿐만 아니라 사회경제적 비용에 커다란 영향을 끼친다. Lee 등[11]에 따르면 우리나라의 비만 으로 인한 사회경제적손실 비용은 2015년 기준 9.2조 원으로써 최근 10 년간 약 두 배 증가하였다. 이와 같은 비만의 심각함을 고려했을 때 비만을 아동시기부터 예 방·관리하는 일은 무엇보다도 중요하다고 할 수 있다. 아동비만전문가들은 아동시기의 비만을 효과적으로 중 재하기 위해서는 식생활과 신체활동 습관을 변화시켜 야 한다고 제시하였다[12]. WHO 역시 아동·청소년 비 만을 예방하기 위한 방법으로 식생활과 신체활동의 접 근을 제시하고 있다. 식생활의 측면에서는 지방과 당을 통한 에너지 섭취를 제한하고 채소, 과일, 콩류, 미정제 곡물, 견과류 섭취를 권장하고 있고 신체활동의 측면에 서는 매일 60 분의 규칙적인 신체활동을 권장하고 있다 [13] 미국 또한 미국인을 위한 식생활지침 [14] 과 신체 활동지침 [15]을 통하여 건강한 식생활과 신체활동을 권 장하고 있다. 그럼에도 불구하고 전 세계적으로 아동·청 소년의 TV 시청, 인터넷 사용, 스마트폰 사용 등과 같은 좌식생활시간은 증가하고 있고 신체활동 시간은 감소하 고 있으며 [16] 가당 탄산음료, 고칼로리 음식 섭취 등의 건강하지 못한 식생활 패턴은 증가하고 있다.

국민건강영양조사에 따르면 우리나라 아동·청소년의 10 명중 2명(중학생 $16.7 \%$, 고등학생 $11.3 \%$ )만이 신체 활동 권장량에 미치는 신체활동을 실천하고 있고 라면, 패스트푸드, 탄산음료 섭취 등 건강하지 못한 식생활 패
턴은 점점 증가하고 있는 추세이다[17]. 따라서 우리나 라 아동·청소년의 식생활과 신체활동 습관 개선을 위한 국가정책 차원의 효과적인 비만예방관리 프로그램이 필 요한 실정이다. 그러므로 본 연구의 목적은 비만예방관 리 정책의 일환으로 실행된 프로그램을 고찰하여 국가 비만예방관리 프로그램 도입 시 그 구성요소를 제시하 는데 있다. 국내에서는 정책의 일환으로 실행한 프로그 램의 효과평가가 전무한 수준이기 때문에 본 연구에서는 국외에서 진행된 아동비만예방관리 프로그램에 사용된 중재의 종류를 파악하고 프로그램의 효과를 파악하였다.

\section{연구방법}

본 연구는 과학적으로 효과가 입증된 아동비만예방 관리 프로그램을 도출 하는데 목적이 있으므로 체계적 으로 문헌을 고찰하여 근거를 제시하여야 한다. 하지만 1 인 연구자가 체계적 문헌고찰을 수행하였을 경우 여 러 가지 제한점이 있기 때문에, 주로 한정된 자원과 시 간 안에 정책의 근거를 만들기 위하여 사용하는 방법인 rapid review[18]를 선택하였다. Rapid review의 장 점은 체계적 문헌고찰에서 요구하는 단계들을 최소화 할 수 있어 보다 빠르게 현재 연구들의 트렌드를 도출 할 수 있다는 점이다.

\section{가. 문헌검색 방법}

Rapid review를 위해서 아동비만예방관리 프로그 램에 연관된 키워드인 “child obesity”, "child obesity program”, “Child obesity intervention”등 이 도출 되었고 이 키워드를 사용하여 정책의 일환으로 진행 된 연구를 찾기 위해 NICE Evidence Search, Open Grey, Grey Literature Report, National Cancer institute(research-tested intervention programs) 등의 데이터베이스에서 문헌검색을 실시하였다. 최신 트렌드를 반영하기 위해서 2010년 이전에 실행된 연구 는 검색대상에서 제외하였고 검색 기간은 2010년 1월 1일부터 2018년 6월 30일까지로 하였다.

\section{나. 선택과정 및 데이터 추출}

검색된 문헌들은 제목, 초록, 그리고 전체 텍스트 순으로 스 크린 되었고 데이터는 사전에 개발된 틀을 사용하여 저자(출판 연도), 프로그램 명, 설계, 참여자 나이(국가), 참여인원, 장소, 중 재, 기간, 결과(비만관련) 순으로 추출하였다. 


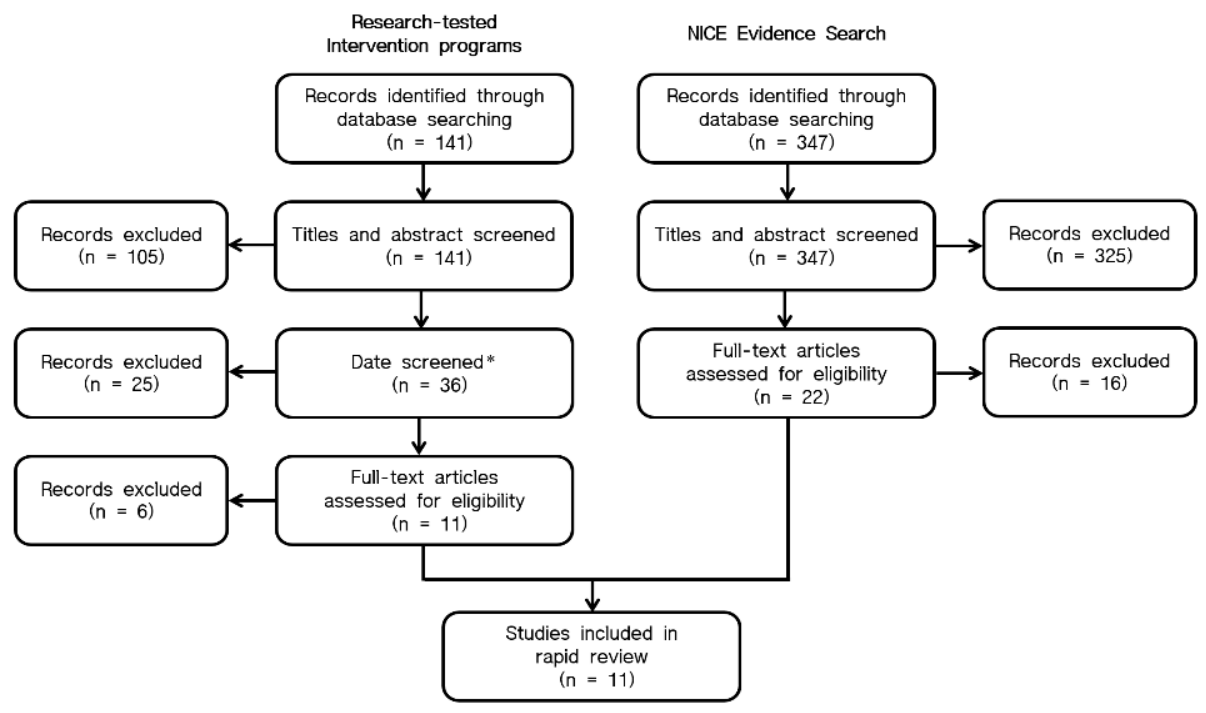

Figure 1. Flow diagram of study selection.

\section{결과}

\section{가. 문헌검색 결과}

자료 선정기준에 따라 문헌검색을 진행한 결과 488 편의 문헌이 검색되었고 제목, 초록 등의 스크리닝 후 남은 33편으로 full-text 스크리닝을 진행하였다. Fulltext 스크리닝 결과 본 리뷰에 사용된 문헌은 총 11편이 었다<Table 1>. 자료 선정 과정은 [Figure 1]과 같다.

\section{나. 연구방법과 장소}

본 리뷰에 사용된 11 편의 연구들은 모두 $\mathrm{RCT}$ (randomized control trial)를 사용하였다. 11편 의 연구들 중 5편은 미국 [19-21, 23, 26], 4편은 영국 $[22,25,28,29]$ 에서 진행되었고 호주[24]와 노르웨 이[27]에서 각각 1 편씩 진행되었다. 연구대상자의 연 령 대는 5-16세였고, 연구가 진행된 장소는 학교가 6편 [19, 21, 22, 24-26], 가정이 3편 [20, 28, 29] 그리고 캠프/의료기관[27]과 방과후 교실[23]이 각각 1 편이 었다<Table 2>.

\section{다. 중재방법과 결과}

각 연구들은 다양한 중재방법, 기간, 빈도 등을 사용 하였다. 7편[20, 22, 23, 25-28]의 연구들이 신체활동 과 영양.식생활을 동시에 사용하는 중재방법을 선택했 고 2편 $[19,24]$ 의 연구는 이 두 가지 중재방법에 심리 중재를 더하였다. 그리고 신체활동과 심리 중재[21]를
Table 2. Component and location of obesity intervention programs

\begin{tabular}{|c|c|c|c|c|}
\hline & School & Family & $\begin{array}{l}\text { After } \\
\text { school care }\end{array}$ & $\begin{array}{l}\text { Healthcare } \\
\text { facility/camp }\end{array}$ \\
\hline $\begin{array}{l}\text { Physical activity \& } \\
\text { Diet.Nutrition }\end{array}$ & $3(2)$ & $2(0)$ & $1(1)$ & $1(1)$ \\
\hline $\begin{array}{l}\text { Physical activity } \\
\text { \& Psychological } \\
\text { coaching }\end{array}$ & $1(1)$ & - & - & - \\
\hline Diet.Nutrition & - & $1(0)$ & - & - \\
\hline $\begin{array}{l}\text { Physical activity } \\
\text { \& Diet } \cdot \text { Nutrition } \\
\text { \& Psychological } \\
\text { coaching }\end{array}$ & $2(0)$ & - & - & - \\
\hline
\end{tabular}

사용한 연구와, 영양-식생활 [29]을 독립적으로 사용한 연구는 각각 1 편씩이었다. 신체활동과 영양.식생활 중 재를 동시에 사용한 연구 중 본 리뷰의 관심변인인 비 만관련 변인(BMI, BMI $z$-score 등)의 변화가 유의하 게 나타난 연구는 4 편 $[22,23,26,27]$ 이었다. 신체활 동과 영양-식생활, 그리고 심리 중재를 동시에 사용한 연구와 영양-식생활 중재만 사용한 연구에서는 비만관 련 변인의 변화가 나타나지 않았다. 신체활동과 심리 중 재를 사용한 연구에서는 비만관련 변인의 변화가 유의 하게 나타났다[21].

1) 신체활동 \& 영양·식생활 중재

Fairclough et al.[22]이 진행한 'CHANGE' 프로그 
Table 1. The characteristics of included studies

\begin{tabular}{|c|c|c|c|c|c|c|c|c|}
\hline $\begin{array}{l}\text { Author, Date } \\
\text { (Ref) }\end{array}$ & $\begin{array}{l}\text { Program } \\
\text { Name }\end{array}$ & $\begin{array}{l}\text { Study } \\
\text { Design }\end{array}$ & $\begin{array}{l}\text { Sample } \\
\text { Size }\end{array}$ & $\begin{array}{l}\text { Age range } \\
\text { or mean }\end{array}$ & Setting & $\begin{array}{l}\text { Type of } \\
\text { intervention }\end{array}$ & Duration & Results \\
\hline $\begin{array}{l}\text { Neumark- } \\
\text { Sztainer et al., } \\
2010 \\
{[19]}\end{array}$ & New Moves & $\mathrm{RCT}$ & $\begin{array}{l}\mathrm{I}=182 \\
\mathrm{C}=174\end{array}$ & $\begin{array}{l}15.8 \text { years } \\
\text { (USA) }\end{array}$ & school & $\begin{array}{l}\text { physical activity, } \\
\text { diet/nutrition \& } \\
\text { behaviour }\end{array}$ & 16 weeks & BMI reduction(not sig, $p=0.512$ ) \\
\hline $\begin{array}{l}\text { Rosenkranz, } \\
\text { Behrens, \& } \\
\text { Dzewaltowski, } \\
2010 \\
{[20]}\end{array}$ & $\begin{array}{l}\text { Healthier Troops in } \\
\text { a SNAP (Scouting } \\
\text { Nutrition \& Activity } \\
\text { Program) }\end{array}$ & $\mathrm{RCT}$ & $\begin{array}{l}\mathrm{I}=34 \\
\mathrm{C}=42\end{array}$ & $\begin{array}{l}\text { 9-13 years } \\
\text { (USA) }\end{array}$ & family & $\begin{array}{l}\text { physical activity \& } \\
\text { diet/nutrition }\end{array}$ & 4 months & $\begin{array}{l}\text { BMI z-score reduction(not sig. } \\
\left.\left(F_{1,5}=0.42, p=0.544\right)\right)\end{array}$ \\
\hline $\begin{array}{l}\text { Melnyk et al., } \\
2013 \\
{[21]}\end{array}$ & $\begin{array}{l}\text { COPE (Creating } \\
\text { Opportunities } \\
\text { for Personal } \\
\text { Empowerment) } \\
\text { Healthy Lifestyles } \\
\text { TEEN (Thinking, } \\
\text { Emotions, Exercise, } \\
\text { and Nutrition) } \\
\text { Program }\end{array}$ & $\mathrm{RCT}$ & $\begin{array}{l}I=358 \\
C=421\end{array}$ & $\begin{array}{l}\text { 14-16 years } \\
\text { (USA) }\end{array}$ & school & $\begin{array}{l}\text { physical activity \& } \\
\text { behaviour }\end{array}$ & 15 weeks & $\begin{array}{l}\text { lower BMI than control group } \\
(p=0.01) \text { at post intervention } \\
-6 \text { months follow up lower BMI } \\
(p=0.00) \\
-6 \text { months follow up } \\
\text { overweight rate reduction (chi- } \\
\text { square }=4.69, p=0.03 \text { ) }\end{array}$ \\
\hline $\begin{array}{l}\text { Fairclough et al., } \\
2013 \\
{[22]}\end{array}$ & $\begin{array}{l}\text { Children's } \\
\text { Health, Activity } \\
\text { and Nutrition: } \\
\text { Get Educated! } \\
\text { (CHANGE!) }\end{array}$ & $\mathrm{RCT}$ & $\begin{array}{l}I=166 \\
C=152\end{array}$ & $\begin{array}{l}\text { 10-11 years } \\
\text { (UK) }\end{array}$ & school & $\begin{array}{l}\text { physical activity \& } \\
\text { diet/nutrition }\end{array}$ & 20 weeks & $\begin{array}{l}\text { group difference in waist } \\
\text { circumference } \\
\beta \text { for intervention effect } \\
=-1.63(95 \% \mathrm{Cl}=-2.20,-1.07) \\
\mathrm{cm}, p<0.001, \mathrm{BMI} \mathrm{Z} \text { score } \\
\text { reduction( } 30 \text { weeks follow } \\
\text { up }(\beta=-0.24(95 \% \mathrm{Cl}=-0.48 \\
-0.003), p=0.04)\end{array}$ \\
\hline $\begin{array}{l}\text { Annesi, Smith, } \\
\text { Walsh, Mareno, } \\
\text { \& Smith, } 2016 \\
\text { [23] }\end{array}$ & Youth Fit 4 Life & $\mathrm{RCT}$ & $\begin{array}{l}\mathrm{I}=72 \\
\mathrm{C}=42\end{array}$ & $\begin{array}{l}5-8 \text { years } \\
\text { (USA) }\end{array}$ & $\begin{array}{l}\text { after } \\
\text { school } \\
\text { class }\end{array}$ & $\begin{array}{l}\text { physical activity \& } \\
\text { diet/nutrition }\end{array}$ & 12 weeks & $\begin{array}{l}\text { treatment group had less } \\
\text { increase in } \operatorname{BMI}\left(t_{112}=2.60 \text {, }\right. \\
p=0.011, E S=0.15)\end{array}$ \\
\hline $\begin{array}{l}\text { Waters et al., } \\
2017 \\
{[24]}\end{array}$ & $\begin{array}{l}\text { Fun'n healthy in } \\
\text { Moreland! }\end{array}$ & $\mathrm{RCT}$ & $\begin{array}{l}\mathrm{I}=1426 \\
\mathrm{C}=1539\end{array}$ & $\begin{array}{l}5-12 \text { years } \\
\text { (Aus) }\end{array}$ & school & $\begin{array}{l}\text { physical activity, } \\
\text { diet/nutrition \& } \\
\text { behaviour }\end{array}$ & 3.5 years & $\begin{array}{l}\text { no significant group effect on } \\
\text { prevalence of overweight and } \\
\text { obesity, BMI z score }(p=0.44)\end{array}$ \\
\hline $\begin{array}{l}\text { Adab et al., } 2018 \\
{[25]}\end{array}$ & WAVES study & $\mathrm{RCT}$ & $\begin{array}{l}I=660 \\
C=732\end{array}$ & $\begin{array}{l}\text { 6-7 years } \\
\text { (UK) }\end{array}$ & school & $\begin{array}{l}\text { physical activity \& } \\
\text { diet/nutrition }\end{array}$ & $\begin{array}{l}12 \\
\text { months }\end{array}$ & $\begin{array}{l}\text { BMI z score lower in } \\
\text { intervention group (not sig. } \\
p=0.18 \text { ) }\end{array}$ \\
\hline $\begin{array}{l}\text { Bogart et al., } \\
2016 \\
{[26]}\end{array}$ & $\begin{array}{l}\text { Students for } \\
\text { Nutrition and } \\
\text { Exercise (SNaX) }\end{array}$ & $\mathrm{RCT}$ & $\begin{array}{l}\mathrm{I}=829 \\
\mathrm{C}=539\end{array}$ & $\begin{array}{l}\text { 12-13 years } \\
\text { (USA) }\end{array}$ & school & $\begin{array}{l}\text { physical activity \& } \\
\text { diet/nutrition }\end{array}$ & 5 weeks & $\begin{array}{l}2 \text { years follow up results: Obese } \\
\text { student in intervention group } \\
\text { showed significant reductions } \\
\text { in BMI percentile } \\
(b=-2.33 \text { percentiles; } S E, 0.83 \text {; } \\
p=0.005)\end{array}$ \\
\hline $\begin{array}{l}\text { Benestad et al., } \\
2017 \\
{[27]}\end{array}$ & $\begin{array}{l}\text { Camp- } \\
\text { based family } \\
\text { treatment of } \\
\text { childhood obesity }\end{array}$ & $\mathrm{RCT}$ & $\begin{array}{l}\mathrm{I}=38 \\
\mathrm{C}=31\end{array}$ & $\begin{array}{l}\text { 7-12 years } \\
\text { (Norway) }\end{array}$ & $\begin{array}{l}\text { primary } \\
\text { care/ } \\
\text { camp }\end{array}$ & $\begin{array}{l}\text { physical activity \& } \\
\text { diet/nutrition }\end{array}$ & 2 years & $\begin{array}{l}\text { Intervention group had a } \\
\text { significantly lower increase in } \\
\text { BMI after } 2 \text { years }(-0.8) \mathrm{kg} / \mathrm{m} 2\end{array}$ \\
\hline $\begin{array}{l}\text { Robertson et al., } \\
2017 \\
{[28]}\end{array}$ & Families for Health & $\mathrm{RCT}$ & $\begin{array}{l}\mathrm{I}=56 \\
\text { families } \\
\mathrm{C}=59 \\
\text { families }\end{array}$ & $\begin{array}{l}\text { 6-11 years } \\
(\mathrm{UK})\end{array}$ & family & $\begin{array}{l}\text { physical activity \& } \\
\text { diet/nutrition }\end{array}$ & 10 weeks & $\begin{array}{l}\text { BMI z score not significantly } \\
\text { different between intervention } \\
\text { and control group ( } p=0.053)\end{array}$ \\
\hline $\begin{array}{l}\text { Fulkerson et al., } \\
2015 \\
{[29]}\end{array}$ & HOME Plus & $\mathrm{RCT}$ & $\begin{array}{l}\mathrm{I}=81 \\
\mathrm{C}=79\end{array}$ & $\begin{array}{l}8-12 \text { years } \\
\text { (UK) }\end{array}$ & family & diet/nutrition & $\begin{array}{l}10 \\
\text { months }\end{array}$ & $\begin{array}{l}\text { no significant BMI z score } \\
\text { difference between groups } \\
\text { (SE=0.04; } 95 \% \mathrm{Cl}:-0.05,0.12 \text {; } \\
p=0.43 \text { ) }\end{array}$ \\
\hline
\end{tabular}

※ I= intervention group, $\mathrm{C}=$ control group 
램은 clustered RCT를 사용하여 12 개 참여 학교를 실 험군 또는 대조군으로 편성하고 실험군에는 사회인지이 론을 기반으로 한 신체활동과 영양.식생활 프로그램을 제공하였다. 이 프로그램은 실제 교과과정에 편성되어 운영방법에 대해 교육 받은 선생님이 운영하였다. 20주 간프로그램을 운영한 결과 실험군 아동들의 허리둘레 감소가 대조군의 아동들 보다 크게 나타났고 $(\mathrm{p}<0.001)$ 30주 후(follow up)에는 BMI z score 역시 감소 차이 가 발생하였다 $(\mathrm{p}=0.04)$.

Annesi, Smith, Walsh, Mareno, \& Smith[23]가 진행한 'Youth Fit 4 Life'는 YMCA가 운영하는 방과후 교실에서 개인효능/사회인지이론을 기반으로 한 신체 활동, 영양·식생활 프로그램을 제공 하였다. 72 명의아 동이 실험군에 그리고 42 명의 아동이 대조군으로 무작 위로 배정되었고 기존의 방과후 교사가 프로그램을 운 영하였다. 12 주간 프로그램을 운영한 결과 실험군 아동 들의 $\mathrm{BMI}$ 증가속도는 대조군의 아동들 보다 더 낮게 나 타났다 $(\mathrm{p}=0.011)$.

Bogart et al.[26]이 진행한 신체활동과 영양.식생 활 중재를 모두 사용한 또 다른 프로그램인 'SNax'는 10 개의 학교를 실험군과 대조군으로 각각 5 개씩 무작 위 분배하였다. 실험군은 환경개선에 중점을 두어 식품 선택과 신체활동이 용이하게 하고, 학생리더를 양성하 여 $\mathrm{SNax}$ 프로그램을 아동들과 그 가정에게 홍보하게 하였다. 5 주간 프로그램을 운영하고 2 년 후 신체계측을 하여 분석한 결과 실험군 비만아동의 $\mathrm{BMI}$ 백분위수가 대조군 비만아동 대비 2.33 감소하였고 이를 체중으로 환산하면 약 $4.1 \mathrm{~kg}$ 이었다 $(\mathrm{p}=0.005)$.

Benestad et al.[27]은 여름가족 캠프를 사용하여 프로그램을 진행하였다. 이 프로그램은 아동과 부모가 함께 참여하는 프로그램으로써 총 2년에 걸쳐 운영되었 으며 38 명의 아동이 실험군에, 31명의 아동이 대조군에 무작위 배정되었다. 모든 집단은 프로그램 시작 전과 종 료 후 한 번씩의 동기부여(영양-식생활, 신체활동 등)와 신체계측 세션을 가졌고 매달 지역 코디네이터의 방문 이나 전화를 받았다. 여름가족 캠프는 영양.식생활과 신 체활동에 대한 내용으로 구성되었고 2 주간 운영되었다. 여름가족 캠프의 목적은 부모에게 동기를 부여해서 가정 에서 건강한 생활을 실천하게 하는데 있었다. 여름가족 캠프 후에는 주기적으로 영양-식생활, 신체활동 프로그 램을 운영하였다. 그 결과, 실험군 아동의 BMI $z$ score
증가폭은 대조군 아동의 증가폭 보다 작게 나타났다.

Rosenkranz, Behrens, \& Dzewaltowski[20]는 7 개의 걸스카우트단을 선발하여 3 개는 실험군에 나머지 4 개는 대조군으로 무작위 배정하여 'SNAP' 프로그램을 진행하였다. 실험군은 8개 모듈로 이루어진 상호교류 교 육과정을 4 개월에 걸쳐 학습하였다. 교육내용은 부모와 의 신체활동, 식사시간 TV시청 안하기, 가당음료 대신 물마시기 등으로 이루어졌다. 이러한 교육은 연구진에 게 직접 교육받은 각 걸스카우트단의 대장이 직접 진행 하였다. 교육 이외에 15 분의 신체활동 레크리에이션 제 공과 과일, 채소 간식 제공 등의 걸스카우트단 모임 규 칙도 정하였다. 4 개월간 SNAP 프로그램을 운영한 결 과 BMI $z$ score의 차이는 나타나지 않았다 $(\mathrm{p}=0.544)$.

Adab et al.[25]이 진행한 'WAVE' study는 건강한 식생활과 신체활동을 주제로 12 개월간 운영한 프로그 램이다. 이 study에서는 26 개 학교의 660 명 아동이 실 험군으로 28 개 학교의 732 명 아동이 대조군으로 무작 위 배정되었다. 실험군은 30 분의 중강도 이상 신체활동, 요리교실, 6주 영양, 신체활동 프로그램, 그리고 여름방 학동안 활동적으로 지낼 수 있는 정보 등을 제공 받았 다. 그 결과 실험군 아동들의 BMI z score가 대조군의 아동들 보다 더 많이 감소하였으나 통계적으로 유의하 지는 않았다 $(p=0.18)$.

Robertson et al.[28]은 부모 접근방법을 사용한 'Families for Health' 프로그램을 진행하였다. 총 115 가정의 128 아동이 프로그램에 참여했으며 56 가정이 실 험군으로 59 가정이 대조군으로 무작위 배정되었다. 프 로그램은 10 주간 운영되었으며 양육기술, 감정·사회 발 달, 건강한 식생활, 신체활동 등의 내용으로 매주 2.5시 간의 교육이 진행되었다. 프로그램 운영 결과 실험군 아 동의 $\mathrm{BMI}$ 는 대조군 아동의 $\mathrm{BMI}$ 와 유의한 차이가 없었 다 $(\mathrm{p}=0.053)$.

\section{2) 신체활동, 영양·식생활 \& 심리 중재}

Neumark-Sztainer et al.[19]은 12개 학교의 356 명의 여아동을 각각 182 명과 174 명씩 실험군과 대조 군으로 무작위 배정 하였다. 실험군의 아동들은 영양교 육과 자기역량강화가 포함된 체육교실, 개인 동기부여 인터뷰, 점심미팅, 그리고 부모 out reach로 이루어진 중재를 받았다. 16 주의 프로그램 운영 결과 실험군 아 동들의 $\mathrm{BMI}$ 는 감소하고 대조군 아동의 $\mathrm{BMI}$ 는 증가 하 
였으나 두 집단간의 차이는 통계적으로 유의하지 않았 다 $(\mathrm{p}=0.512)$.

Waters et al.[24]이 진행한 'Fun 'n healthy in Moreland!'는 clustered RCT를 사용하여 23개 참여 학교를 실험군 또는 대조군으로 편성하고 식생활 개선 과, 신체활동 증진 및 좌식생활 감소를 목표로 프로그 램을 운영하였다. 프로그램 제공자는 3.5년간 과일, 채 소, 생수 섭취 증가, 신체활동 증진, 학생의 자부심 증 진 등을 골자로 하는 프로그램을 실험군에 속한 학교가 자신들의 실정에 맞게 개발할 수 있게 도움을 주었다. 프로그램 운영결과 분석 가능한 데이터는 실험군에서 1,426 명, 대조군에서는 1,539 명이었다. 실험군과 대조 군의 비만율은 모두 감소하였으나 통계적으로 집단 간 유의한 차이는 나타나지 않았다. BMI z score의 경우 실험군이 더 낮게 나타났으나 이 또한 통계적으로 유의 한 차이는 없었다 $(\mathrm{p}=0.44)$

\section{3) 신체활동 \& 심리 중재}

'COPE'를 진행한 Melnyk et al.[21]은 779명의 학 생을 각각 358명과 421명씩 실험군과 대조군으로 무 작위 배정 하였다. 실험군의 학생들은 15 세션으로 이루 어진 신체활동과 접목된 인지행동기술 프로그램을 제 공 받았다. 각 세션은 $15-20$ 분간의 걷기, 춤 등과 같은 신체활동을 포함하였고 만보기를 제공하여 걸음 수를 $10 \%$ 증가하게 하였다. 이외에도 보건수업에서 인지행 동기술에 관한 내용을 교육하였다. 15 주의 프로그램 진 행 결과 실험군 아동들의 $\mathrm{BMI}$ 는 대조군 아동 보다 통계 적으로 낮게 나타났고( $\mathrm{p}=0.01), 6$ 개월 후의 follow up 에서 역시 낮게 나타났다 $(\mathrm{p}=0.00)$. 또한 실험군의 과체 중률은 대조군보다 낮게 나타났다( $\mathrm{p}=0.03)$.

\section{4) 영양·식생활 중재}

Fulkerson et al.[29]는 사회인지이론과 사회생태 학적 프레임워크에 기반을 둔 영양.식생활 프로그램인 'HOME Plus'를 진행하였다. 160 가정이 연구에 참여하 여 81 가정이 실험군에 79 가정이 대조군으로 무작위 배 정되었다. 이 프로그램은 영양사와 간호사에 의해 운영 되었고 가족과 함께하는 식사를 주제로 진행되었다. 총 10 개월간 프로그램이 운영되었으며 프로그램은 한 달에 한 세션 그리고 다섯 번의 목표설정 전화로 구성되었다. 실험군은 가이드북, 행동변화를 위한 전략, 요리 레시
피 등을 제공받았다. 프로그램 진행결과 실험군과 대조 군간의 BMI $z$ score 차이는 나타나지 않았다 $(\mathrm{p}=0.43)$.

\section{논의}

현재 우리나라 아동·청소년의 식생활 행태와 신체 활동 실천율은 점점 악화되고 있고 그에 따라 비만율은 꾸준히 증가하고 있어 국가차원의 효과적인 아동-청소 년 비만예방 프로그램이 필요한 실정이다. 따라서 본 연 구의 목적은 rapid review를 통하여 효과적인 최신의 비만예방 프로그램의 구성요소를 도출하는데 있었다.

비만의 주요 원인은 유전적인 요인을 제외했을 때 건 강하지 못한 식생활과 부족한 신체활동이라고 할 수 있 다. 따라서 신체활동을 증진 시키고 식생활을 개선하는 중재는 아동비만을 예방하기 위해 매우 적합한 방법이 다. 본 리뷰 결과 대부분의 연구(11편 중 7편)가 신체활 동과 영양-식생활을 동시에 사용하였고 그 대부분(7편 중 4편)에서 긍정적인 효과가 나타났다. 이 결과는 신 체활동과 영양.식생활의 중재를 동시에 진행 할 때 좋은 효과가 보장된다고 제시한 선행 연구결과와도 일치 한 다[30][31]. 따라서 아동 비만예방 프로그램을 구성할 시 신체활동과 영양-식생활 중재가 모두 포함되는 복합 중재방식을 고려해야 할 것이다. 신체활동과 영양.식생 활 중재를 포함한 연구들은 3 편이 학교에서, 2 편이 가정 에서, 그리고 방과후 교실과 의료기관(여름캠프)에서 각 각 1 편씩 진행되었다. 그 중 효과 있는 프로그램은 학교 에서 2편, 방과후 교실과 의료기관(여름캠프)에서 각각 1 편이었고 가정에서의 프로그램은 효과가 나타나지 않 았다. 따라서 신체활동과 영양.식생활을 동시에 사용하 는 프로그램은 학교나 방과후 교실 그리고 의료기관에서 운영하는 것이 좋을 것으로 생각된다. 선행 연구들은 아 동·청소년이 하루에 6-8시간을 학교에서 보내기 때문에 학교에서 비만예방프로그램을 진행할 경우 효율적 [32] 이고 그 효과가 가장 크게 나타난다고 제시하였고 본 연 구에 포함된 'CHANGE!'와 'SNaX'가 이에 해당한다.

본 리뷰 결과 비만관련 변인에 대한 개선 효과가 나 타난 또 다른 중재방법은 신체활동과 심리중재를 동시 에 사용한 중재였으며 11 편의 연구 중 1 편이 이에 해당 하였다. 심리중재는 주로 행동변화에 관점을 맞추고 있 는데 동기부여 인터뷰, 목표 설정, 긍정적인 생각의 강 화, 모니터링, 인지 재구성 등이 이에 해당된다[33]. 선 
행 연구들은 심리중재가 비만관련 변인에 끼치는 긍정 적인 결과를 꾸준히 보여주었다[34-36]. 이러한 심리 중재가 신체활동량을 증진시켜 칼로리를 소모하게 하 는 신체활동 중재와 같이 병행되면 그 효과는 더 커진 다고 할 수 있으며 본 리뷰에 포함된 'COPE Healthy Lifestyles TEEN' 프로그램이 그 예라고 할 수 있다. 신체활동과 영양.식생활 그리고 심리중재를 동시에 사 용하여 아동비만을 중재한 연구(2편)는 비만관련 변인 에 대한 효과가 없는 것으로 나타났다. 성인의 경우 신 체활동, 영양.식생활의 복합중재에 카운셀링 같은 심리 적인 중재가 추가되면 그 결과는 더욱 효과적으로 나타 나지만[37] 본 리뷰 결과 아동·청소년에게는 그 효과 가 나타나지 않았다. 그러나 미국, 영국, 호주와 같은 해 외 주요국가의 비만관리지침 [38-40]에서는 신체활동, 영양-식생활, 그리고 행동변화(심리) 중재를 동시에 사
용하기를 권고하고 있고 본 리뷰에 포함된 연구의 사례 수가 1 편인 것을 생각했을 때 위의 세 가지 중재를 동시 에 사용하는 방법이 효과가 없다고 결론 내리기는 힘들 다고 할 수 있다. 따라서 추후 연구를 통해 세 가지 복합 중재의 효과를 고찰해야 할 것이다.

영양·식생활 중재만을 사용한 프로그램 역시 그 효 과가 없는 것으로 나타났는데 본 리뷰에서 포함한 11 편의 연구 중 1 편이 이에 해당된다. 선행 연구는 영양. 식생활의 중재가 규칙적인 운동이나 신체활동과 병행 되지 않으면 그 효과가 뚜렷하지 않다고 보고하고 있다 [41]. 따라서 아동비만예방관리 프로그램을 디자인 할 때는 앞서 언급한 'CHANGE!'와 'SNaX' 같이 영양-식 생활과 신체활동의 중재가 동시에 들어가는 프로그램을 고려해야 할 것이다 〈Table 3 >

본 리뷰의 결과는 몇 가지의 제한점이 있다. 첫째,

Table 3. CHANGE! and SNaX program

\section{CHANGE!}

CHANGE!는 Children's Health, Activity and Nutrition: Get Educated!의 약자로써 학교를 기반으로 하여 10 세에서 11 세의 아동에게 영양교육과 신체활동을 제공하는 영국의 프로그램이다. 이 프로그램의 목적은 건강체중 만들기에 있고 사회인지이론을 기반으로 개발되어 개인의 행동과 사회·물리적 환경의 교류에 포커스를 맞추고 있 다. 2 시간의 훈련을 받은 선생님들이 교과과정과 연계하여 20 주 동안 하루에 한 시간씩 프로그램을 진행하고 학 생들은 영양과 신체활동에 대하여 논의하고 탐구하며 배우게 된다.

신체활동시간은 “많이 움직이고 덜 앉자”라는 메시지를 포함하고 있으며 신체활동량을 늘리고 좌식생활을 줄이 는 목적을 가지고 진행된다. 특정한 신체활동을 하기 보다는 학생들을 활동적이게 하는 것이 장려된다. 이 프로그 램은 기본적인 신체활동에 관련된 지식과 목표 정하기, 신체활동량 모니터링 하기, 체력 정보 제공 등으로 구성된 다. 영양교육은 에너지(칼로리) 균형, 다량영양소, 그리고 식습관으로 구성된다. 학생들은 탄수화물 지방, 당 같은 식품구성 영양소, 식품영양표시, 건강한 음료섭취 등을 배우고 과일과 채소 섭취, 건강한 아침 먹기, 건강한 간식 선택하기 등도 배운다. 선생님은 워크시트와 수업용 매체를 사용하여 프로그램을 계획하고 학생들은 가족들과의 활동이 포함된 신체활동과 영양관련 숙제를 하게 된다.

\section{$\mathrm{SNaX}$}

$\mathrm{SNaX}$ 는 Students for Nutrition and Exercise의 약자로써 캘리포니아주의 중학교에서 건강한 식생활과 신체활 동을 장려하는 프로그램이다. 이 프로그램은 학교 전체가 참여하여 건강한 식생활을 위한 환경을 만든다. $\mathrm{SNaX}$ 프로그램은 총 5 주로 구성되어 있으며 학생들은 1 주차에 건강한 음료, 2 주차에 구내식당에서 음식선택하기, 3 주 차에 건강한 식생활의 이점, 4 주차에 신체활동, 마지막으로 5 주차에 미디어에 대하여 배우게 된다. 매주 25 명의 학생들이 리더로 뽑히게 되고 매주 화요일 점심시간에 리더들은 프로그램 강사에게 신체활동과 영양에 관한 다양 한 교육을 받게 된다. 그 후, 수요일에 리더들은 카운셀링 기술을 연습하여 반 친구들에게 강사에게서 배운 신체활 동과 영양관련 지식을 전파하게 된다. $\mathrm{SNaX}$ 프로그램은 디자이너들과 협업하여 학생들의 건강한 식생활과 신체 활동을 장려하는 포스터 역시 제작한다. 현재 $\mathrm{SNaX}$ 프로그램은 모바일 어플로도 개발되어 사용되고 있다. 
시간의 제약에 따라 비만예방관리 프로그램의 효과평 가를 비만 관련 변인인 BMI나 BMI $z$ score 등만 사용 하였다는 점이다. 대부분의 비만예방관리 프로그램 연 구들은 primary outcome으로 BMI 혹은 비만율 등을 체택하고 secondary outcome으로 신체활동량이나 식 습관을 평가하고 있다. 단기간의 중재를 통해 비만관 련 변인의 변화가 없더라도 신체활동이나 식생활 습관 에 영향을 끼쳐 장기적으로 봤을 때 그 효과가 긍정적 으로 나타날 수 있기 때문이다. 따라서 본 리뷰 결과 효 과가 없다고 나타난 프로그램들도 secondary outcome 을 고찰 한다면 그 효과가 유의하게 나타날 수 도 있다. 그러므로 추후 연구에서는 신체활동과 영양·식생활 관 련 태도, 지식, 실천 등도 프로그램의 효과평가를 위한 변인에 포함시켜야 할 것이다. 둘째, 본 리뷰에 포함된 일차 연구의 결과가 한 방향으로 나오지 않고 양 방향 (mixed)으로 나온 이유는 RCT가 아동비만예방관리 프 로그램의 효과를 평가하기에는 적합하지 않기 때문일 수도 있다. 아동비만예방관리 프로그램의 목적은 비만 관련 변인과 비만관련 행동/행태의 개선에 그 목적이 있다. 이러한 프로그램의 연구에 RCT를 적용했을 경우 집단 간의 결과 비교를 하는 RCT는 집단내의 개선효과 를 밝혀내기 어렵고 연구기간이 길어지면 길어질수록 집단의 통제(control)가 어려워져 실험군과 대조군에 게 적용되는 중재의 구분이 명확해지지 않는다는 약점 이 있기 때문이다. 따라서 아동비만예방관리 프로그램 의 효과를 분석하려면 실험군의 사전 사후 비교를 하는 quasi-experiment 연구나 natural experiment 연구가 더 적합할 수 있다. 정책의 일환으로 진행된 본 리뷰에 포함된 연구들은 모두 RCT를 사용했기 때문에 추후 연 구에서는 학술연구의 일환으로 진행된 아동비만예방관 리 프로그램 역시 포함하여 리뷰를 수행한다면 더 많은 연구를 확보하여 더욱 객관적인 결과를 도출할 수 있을 것이라고 생각된다. 마지막으로 본 리뷰는 국외에서 정 책의 일환으로 진행된 프로그램만을 대상으로 수행하였 기 때문에 리뷰 결과를 일반화하는데 어려움이 있을 수 있다. 하지만 정부의 예산이 투입되어 정책적으로 진행 된 효과적인 프로그램의 구성요소를 파악하여 우리나 라의 정책결정자가 국가차원의 비만프로그램을 도입할 때 그 구성요소에 대한 근거를 마련하였다는 점에서 의 의가 있다고 생각된다.

\section{결론}

문헌검색 및 스크리닝 결과 본 연구의 목적에 맞는 아동비만예방 프로그램은 11 편이었으며 대부분의 연구 가 신체활동과 영양.식생활을 동시에 사용하였다. 또한 대부분의 연구는 학교에서 운영되었고 5 편의 연구에서 비만관련 변인 개선의 효과성이 나타났다. 효과가 있는 중재방법은 신체활동과 영양.식생활을 동시에 사용하는 방법과 신체활동과 심리중재를 동시에 사용하는 방법이 었다. 신체활동과 영양.식생활 그리고 심리중재를 사용 하는 방법과 영양.식생활만 사용한 방법은 효과성이 나 타나지 않았다. 학교, 의료기관/여름캠프, 방과후 교실 에서는 프로그램의 효과가 나타났고 가정에서 진행된 프 로그램은 그 효과가 나타나지 않았다. 위의 내용을 종합 할 때 아동비만예방 프로그램은 신체활동이 포함된 복합 중재가 효과적일 것이며 중재의 종류는 두 가지가 적절 할 것으로 보인다. 이렇게 디자인된 중재 프로그램을 학 교에서 실행하는 것이 가장 효과적일 것으로 생각된다.

\section{Conflicts of Interest}

The author declares no conflict of interest.

\section{References}

1. Ng M, Fleming T, Robinson M, et al. Global, regional, and national prevalence of overweight and obesity in children and adults during 1980-2013: A systematic analysis for the Global Burden of Disease Study 2013. Lancet. 2014; 384(9945):766-781.

2. Ford ES. The epidemiology of obesity and asthma. J Allergy Clin Immunol. 2005; 115(5):897-909.

3. Goran MI, Ball GDC, Cruz ML. Obesity and risk of type 2 diabetes and cardiovascular disease in children and adolescents. J Clin Endocrinol Metab. 2003; 88(4):1417-1427.

4. Freedman DS, Mei Z, Srinivasan SR, Berenson GS, Dietz WH. Cardiovascular Risk Factors and Excess Adiposity Among Overweight Children and Adolescents: The Bogalusa Heart Study. J Pediatr. 2007; 150(1):12-17.e2. 
5. Van Geel M, Vedder P, Tanilon J. Are overweight and obese youths more often bullied by their peers? A metaanalysis on the relation between weight status and bullying. Int J Obes. 2014; 38(10):1263-1267.

6. World Health Organization. World Health Organization. 2018; https://www.who.int/news-room/fact-sheets/ detail/obesity-and-overweight (accessed July 5, 2020)

7. The Ministry of Health and Welfare. A study on obesity plan for children and adolescents. 2014.

8. Whitaker RC, Pepe MS, Wright JA, Seidel KD, Dietz WH. Early adiposity rebound and the risk of adult obesity. Pediatrics. 1998; 101(3):E5.

9. Ward ZJ, Long MW, Resch SC, Giles CM, Cradock AL, Gortmaker SL. Simulation of growth trajectories of childhood obesity into adulthood. N Engl J Med. 2017; 377(22):2145-2153.

10. Bass R, Eneli I. Severe childhood obesity: An underrecognised and growing health problem. Postgrad Med J. 2015; 91(1081):639-645.

11. Lee SM, Baek JH, Kim JH, Kang HR. A study for extending healthy life expectancy: Improving NHIS's obesity program. National Health Insurance Service. 2017.

12. Barlow SE; Expert Committee. Expert committee recommendations regarding the prevention, assessment, and treatment of child and adolescent overweight and obesity: summary report. Pediatrics. 2007; 120 Suppl 4:S164-S192.

13. World Health Organization (WHO). Report of the Commission on Ending Childhood Obesity. Implementation plan: executive summary. Geneva. 2017.

14. U.S. Department of Health and Human Services and U.S. Department of Agriculture. 2015-2020 Dietary Guidelines for Americans. 8th Edition. 2015.

15. Piercy KL, Troiano RP, Ballard RM, et al. The Physical Activity Guidelines for Americans. JAMA. 2018; 320(19):2020-2028.

16. World Health Organization (WHO). Children's Environmental Health: Emerging issues. Geneva. 2015. 17. KCDC. 2018 Korea National Health and Nutrition Examination Surveys. 2019.
18. Haby MM, Chapman E, Clark R, Barreto J, Reveiz L, Lavis JN. What are the best methodologies for rapid reviews of the research evidence for evidence-informed decision making in health policy and practice: a rapid review. Health Res Policy Syst. 2016; 14(1):83.

19. Neumark-Sztainer D, Friend S, Flattum C et al. New Moves-Preventing Weight-Related Problems in Adolescent Girls. Am J Prev Med. 2010; 39(5):421-432.

20. Rosenkranz R, Behrens T, Dzewaltowski D. A grouprandomized controlled trial for health promotion in Girl Scouts: Healthier Troops ina SNAP (Scouting Nutrition \& Activity Program). BMC Public Health. 2010; 10(1).

21. Melnyk B, Jacobson D, Kelly S et al. Promoting Healthy Lifestyles in High School Adolescents. Am J Prev Med. 2013; 45(4):407-415.

22. Fairclough S, Hackett A, Davies I et al. Promoting healthy weight in primary school children through physical activity and nutrition education: a pragmatic evaluation of the CHANGE! randomised intervention study. BMC Public Health. 2013; 13(1).

23. Annesi J, Smith A, Walsh S, Mareno N, Smith K. Effects of an after-school care-administered physical activity and nutrition protocol on body mass index, fitness levels, and targeted psychological factors in 5- to 8-year-olds. Transl Behav Med. 2015; 6(3):347-357.

24. Waters E, Gibbs L, Tadic M et al. Cluster randomised trial of a school-community child health promotion and obesity prevention intervention: findings from the evaluation of fun ' $n$ healthy in Moreland!. BMC Public Health. 2017; 18(1).

25. Adab P, Pallan M, Lancashire E et al. Effectiveness of a childhood obesity prevention programme delivered through schools, targeting 6 and 7 year olds: cluster randomised controlled trial (WAVES study). BMJ. 2018; $\mathrm{k} 211$.

26. Bogart L, Elliott M, Cowgill B et al. Two-Year BMI Outcomes From a School-Based Intervention for Nutrition and Exercise: A Randomized Trial. Pediatrics. 2016; 137(5):e20152493-e20152493.

27. Benestad B, Lekhal S, Småstuen M et al. Camp-based 
family treatment of childhood obesity: randomised controlled trial. Arch Dis Child. 2016; 102(4):303-310.

28. Robertson W, Fleming J, Kamal A et al. Randomised controlled trial evaluating the effectiveness and costeffectiveness of 'Families for Health', a family-based childhood obesity treatment intervention delivered in a community setting for ages 6 to 11 years. Health Technol Assess (Rockv). 2017; 21(1):1-180.

29. Fulkerson J, Friend S, Flattum C et al. Promoting healthful family meals to prevent obesity: HOME Plus, a randomized controlled trial. International Journal of Behavioral Nutrition and Physical Activity. 2015; 12(1).

30. McGovern L, Johnson JN, Paulo R, et al. Clinical review: treatment of pediatric obesity: a systematic review and meta-analysis of randomized trials. J Clin Endocrinol Metab. 2008; 93(12):4600-4605.

31. Shirley K, Rutfield R, Hall N, Fedor N, McCaughey VK, Zajac K. Combinations of obesity prevention strategies in US elementary schools: a critical review. J Prim Prev. 2015; 36(1):1-20.

32. Wang LY, Yang Q, Lowry R, Wechsler H. Economic analysis of a school-based obesity prevention program. Obes Res. 2003; 11(11):1313-1324.

33. Davis MM, Gance-Cleveland B, Hassink S, Johnson R, Paradis G, Resnicow K. Recommendations for prevention of childhood obesity. Pediatrics. 2007; 120 Suppl 4:S229-S253.

34. Bauer S, de Niet J, Timman R, Kordy H. Enhancement of care through self-monitoring and tailored feedback via text messaging and their use in the treatment of childhood overweight. Patient Educ Couns. 2010; 79(3):315-319.

35. Tsiros MD, Sinn N, Brennan L, et al. Cognitive behavioral therapy improves diet and body composition in overweight and obese adolescents. Am J Clin Nutr. 2008; 87(5):1134-1140.

36. Shaw K, O’Rourke P, Del Mar C, Kenardy J. Psychological interventions for overweight or obesity. Cochrane Database Syst Rev. 2005; (2):CD003818.

37. Hardcastle S, Taylor A, Bailey M, Castle R. A randomised controlled trial on the effectiveness of a primary health care based counselling intervention on physical activity, diet and CHD risk factors. Patient Educ Couns. 2008; 70(1):31-39.

38. National Institute for Health and Care Excellence(NICE). Obesity: Identification, Assessment and Management. 2014.

39. US Preventive Services Task Force, Curry SJ, Krist AH, et al. Behavioral Weight Loss Interventions to Prevent Obesity-Related Morbidity and Mortality in Adults: US Preventive Services Task Force Recommendation Statement. JAMA. 2018; 320(11):1163-1171.

40. National Health and Medical Research Council. Clinical Practice Guidelines for the Management of Overweight and Obesity in Adults, Adolescents and Children in Australia. 2013.

41. Hossain P, Kawar B, El Nahas M. Obesity and diabetes in the developing world--a growing challenge [published correction appears in N Engl J Med. 2007 Mar 1;356(9):973]. N Engl J Med. 2007; 356(3):213-215. 